\title{
REVISÃO
}

\section{EFEITOS BENÉFICOS DAS ISOFLAVONAS DE SOJA EM DOENCAS CRÔNICAS}

\author{
BENEFICIAL EFFECTS OF SOY ISOFLAVONES ON CHRONIC DISEASES
}

\author{
Elizabeth Adriana ESTEVES 1 \\ Josefina Bressan Resende MONTEIRO2
}

\begin{abstract}
RESUMO
Durante as últimas décadas, evidências científicas vêm demonstrando que as isoflavonas podem trazer benefícios no controle de doenças crônicas tais como câncer, diabetes mellitus, osteoporose e doenças cardiovasculares. Estes compostos estão amplamente distribuídos no reino vegetal e concentrações relativamente maiores são encontradas nas leguminosas, em particular, na soja (Glycne max). Além da sua atividade anti-estrogênica, possuem diversas propriedades biológicas que podem afetar muitos processos bioquímicos e fisiológicos. As evidências de que as isoflavonas protegem contra várias doenças crônicas são baseadas em estudos experimentais e epidemiológicos. Em humanos, estudos epidemiológicos mostram uma maior incidência de alguns tipos de câncer (mama, próstata e cólon) e doenças cardiovasculares nas populações ocidentais expostas a limitadas quantidades de isoflavonas de soja na dieta. Evidência adicional para proteção contra o câncer e doenças cardíacas tem sido verificada em vários modelos experimentais com animais. As isoflavonas podem também prevenir a perda óssea pós-menopausa e a osteoporose. Efeitos da genisteína na regulação da secreção de insulina também têm sido demonstrados. Os mecanismos pelos quais as isoflavonas podem exercer estes efeitos parecem depender, em parte, das suas propriedades agonistas-antagonistas dos estrógenos. Outros mecanismos hipotéticos poderiam derivar de outras propriedades bioquímicas, tais como inibição da atividade enzimática e efeito antioxidante.
\end{abstract}

Termos de indexação: isoflavonas, doenças cardiovasculares, neoplasias, osteoporose, diabetes mellitus.

\begin{abstract}
During the last decades, scientific evidences have shown that isoflavones may have influence on chronic diseases control, such as cancer, diabetes mellitus, osteoporosis, and cardiovascular diseases. These compounds are widely found in beans, particularly in soybeans (Glycine max). In addition to their anti-estrogen activity, they have biological properties that may have impact on many biochemical and physiological processes. The evidences that isoflavones protect against chronic diseases are based on experimental and epidemiological studies. In humans, epidemiological studies clearly show a higher incidence of some kinds of cancers (for example: breast, prostate and colon) and cardiovascular diseases in western people that are exposed to limited amounts of soy isoflavones, such as daidzein and genistein, on diets. Additional evidences have been verified in several experimental animal models. The isoflavones may prevent bone loss and osteoporosis in post-menopause women. Effects of genistein on insulin release have also been showed. It seems that their mechanisms of action depend on their estrogen agonist-antagonist properties and other biochemical properties such as enzymatic activity inhibition and antioxidant effects.
\end{abstract}

Index terms: isoflavones, soybean, cardiovascular diseases, neoplasms, osteoporosis, diabetes mellitus.

(1) Departamento de Tecnologia de Alimentos, Universidade Federal de Viçosa.

${ }^{\text {(2) }}$ Departamento de Nutrição e Saúde, Universidade Federal de Viçosa, 36057-100, Viçosa, MG, Brasil. Correspondência para/Correspondence to: J.B.R. MONTEIRO. 


\section{INTRODUÇÃO}

As isoflavonas (também chamadas isoflavonóides) são compostos químicos fenólicos, pertencentes à classe dos fitoestrógenos e estão amplamente distribuídos no reino vegetal. As concentrações destes compostos são relativamente maiores nas leguminosas e, em particular, na soja (Glycine max), sendo que as principais isoflavonas encontradas na soja e seus derivados são a daidzeína, a genisteína e a gliciteína, as quais apresentam-se como várias formas de conjugados glicosídicos, dependendo da extensão do processamento ou fermentação. Do total de isoflavonas, dois terços são de glicosídeos conjugados de genisteína, sendo o restante composto de conjugados de daidzeína e pequenas quantidades de gliciteína. Já nos produtos fermentados de soja, predominam não só a genisteína, mas também a daidzeína, devido a ação de glicosidases bacterianas. Sendo assim, a maior parte da proteína de soja que é utilizada pela indústria de alimentos contém isoflavonas em concentrações variadas (0,1-3,0 mg) (Setchell, 1998).

Nas últimas décadas, tem havido um grande interesse nos fitoestrógenos e em particular nos potenciais benefícios que uma dieta rica nestes compostos pode conferir no controle de muitas doenças crônicas. O maior interesse dos pesquisadores é na farmacologia e fisiologia das isoflavonas, pois apresentam estrutura não esteroidal, mas comportam-se como estrógenos na maioria dos sistemas biológicos, além de serem as mais abundantes dentre os fitoestrógenos. Em adição à sua atividade anti-estrogênica, estes compostos possuem diversas propriedades biológicas (atividade antioxidante, inibição da atividade enzimática e outras) que podem influenciar muitos processos bioquímicos e fisiológicos (Setchell, 1998).

A evidência de que as isoflavonas protegem contra várias doenças crônicas é baseada em estudos experimentais e epidemiológicos. Em humanos, estudos epidemiológicos mostram claramente uma maior incidência de alguns tipos comuns de câncer (mama, próstata e cólon) e doenças cardiovasculares nas populações ocidentais expostas a limitadas quantidades de isoflavonas de soja (por exemplo: daidzeína e genisteína) na dieta. Evidência adicional para proteção contra o câncer e doenças cardíacas, resultantes da administração de isoflavonas de soja, tem sido verificada em vários modelos experimentais com animais. As isoflavonas podem também prevenir a perda óssea pós-menopausa e a osteoporose (Brandi, 1997). Efeitos da genisteína na regulação da secreção de insulina também tem sido demonstrados (Sorenson et al., 1994). Os mecanismos pelos quais as isoflavonas podem exercer estes efeitos parecem depender, em parte, das suas propriedades agonistas-antagonistas dos estrógenos. Outros mecanismos hipotéticos poderiam derivar de outras propriedades bioquímicas, tais como inibição da atividade enzimática e efeito antioxidante (Brandi, 1997).

\section{Metabolismo e ação fisiológica das isoflavonas}

As isoflavonas estão presentes nos alimentos ligadas a açúcares e beta-glicosídeos. Nesta forma não são absorvidas pelo organismo humano. Somente as isoflavonas livres sem a molécula de açúcar, as chamadas agliconas, são capazes de atravessar a membrana plasmática. Enzimas hidrolíticas de bactérias intestinais são responsáveis por estas reações. No lúmen, as bactérias convertem grande parte dessas agliconas em outras moléculas. Existe uma variabilidade considerável na eficiência digestiva das isoflavonas. Somente as formas agliconas ou seus produtos metabólicos são absorvidos pela barreira epitelial do intestino, a qual ocorre passivamente via micelas. Após a absorção, estas moléculas são incorporadas nos quilomícrons, que as transportam ao sistema linfático antes de entrar no sistema circulatório. Os quilomícrons distribuem as isoflavonas em todos os tecidos extra-hepáticos, onde irão exercer seus efeitos metabólicos, antes de retorná-las ao fígado como quilomícrons remanescentes. A retomada das isoflavonas circulantes do sangue ocorre passivamente e todas as células que contêm receptores para estrógenos potencialmente podem ser influenciadas por essas moléculas. Quando estas moléculas são secretadas na bile pelo fígado, parte é reabsorvida pela circulação entero-hepática e parte é excretada pelas fezes. (Anderson \& Garner, 1997), Entretanto, a eliminação urinária das isoflavonas é maior e corresponde a aproximadamente 10 - 30\% da ingestão dietética (Setchell, 1998).

Os efeitos das isoflavonas variam de tecido para tecido e em cada tipo, estas apresentam afinidade por receptores específicos. Tais efeitos ainda não são suficientemente elucidados a nível molecular. Entretanto, estudos tem demonstrado que as isoflavonas possuem mecanismos gerais de ação que podem interferir no metabolismo de muitos nutrientes (Anderson \& Garner, 1997). Um possível mecanismo de ação geral das isoflavonas inclui efeitos estrogênicos e anti-estrogênicos, regulação da atividade de proteínas (especialmente das tirosina quinases), regulação do ciclo celular e efeitos antioxidantes (Figura 1) (Kurzer \& Xu, 1997). Estudos em humanos, animais e sistemas de culturas de células sugerem que as isoflavonas, especificamente a genisteína e a daidzeína desempenham um papel importante na prevenção de doenças crônicas tais como, osteoporose, doenças do coração, câncer e diabetes. 


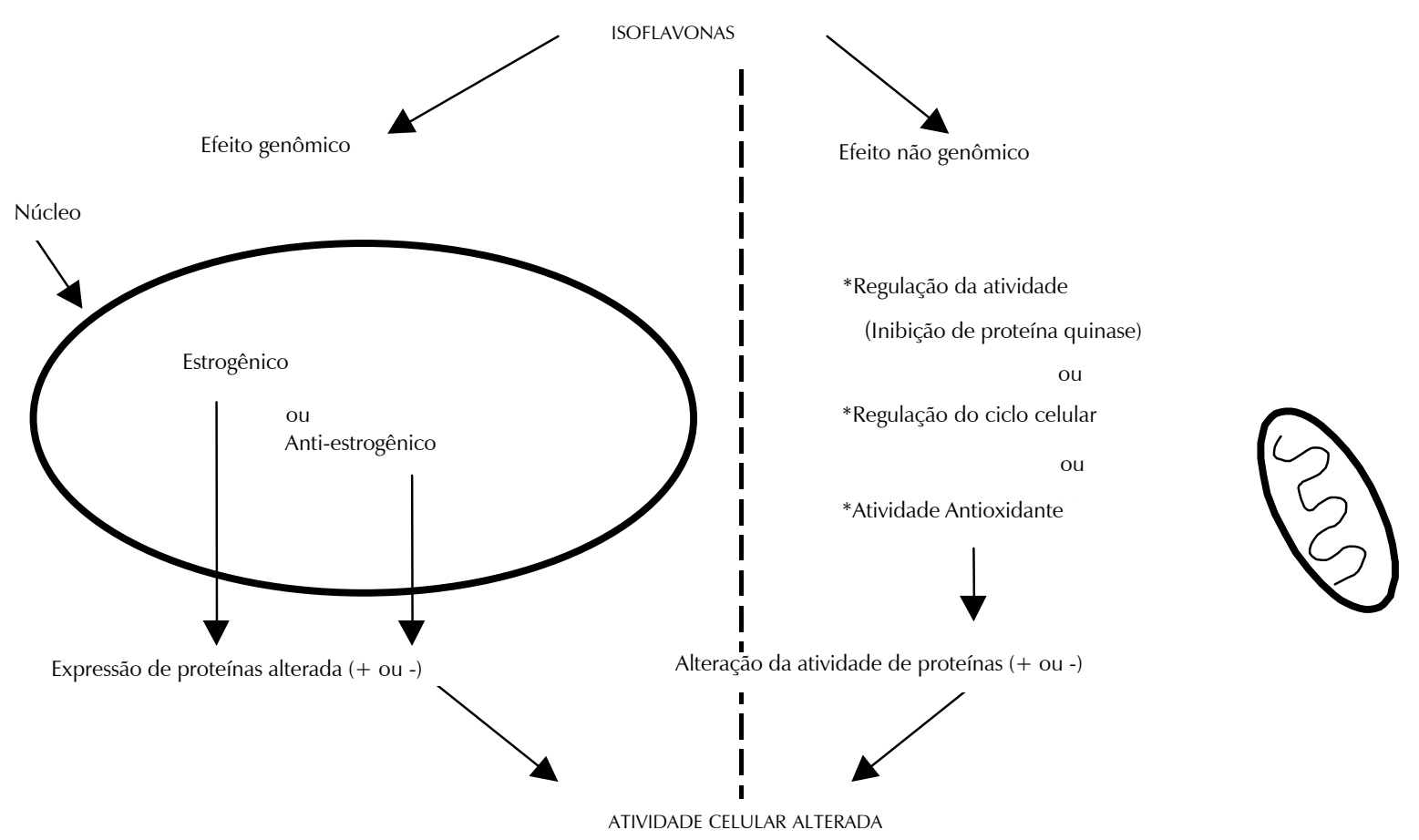

Figura 1. Mecanismo geral de ação das isoflavonas no organismo.

\section{Isoflavonas versus carcinogênese}

O câncer é o crescimento incontrolado de células para formar um tumor que, em alguns casos, pode invadir os tecidos adjacentes e se propagar, por processos de metástases, formando tumores secundários em outras partes do corpo (Cameron \& Pauling, 1979; Tolonem, 1990).

Tem sido demonstrado que as isoflavonas da soja, especificamente a genisteína e a daidzeína, apresentam efeito anti-cancerígeno. Estudos epidemiológicos demonstram que nas populações que consomem dietas ricas em soja e seus produtos, a incidência de determinados tipos de câncer (cólon, mama e próstata, principalmente) é menor quando comparada com a incidência em populações que não consomem esses tipos de dietas. Em adição, acredita-se que a suplementação da dieta com certos produtos da soja, os quais tem mostrado suprimir a carcinogênese em animais, poderia reduzir as taxas de mortalidade por câncer. Os mecanismos relacionando câncer e isoflavonas ainda são alusivos. Tem sido demonstrado que a atividade de várias enzimas, principalmente a topoisomerase II e as tirosina quinases, é inibida pela genisteína e, em alguns casos, por outras isoflavonas. Em adição, outros estudos têm demonstrado propriedades anti-carcinogênicas, anti-oxidativas, efeitos anti-estrogênicos e anti-proliferativos das isoflavonas. Então, pode-se inferir que estas moléculas podem agir de maneiras diferentes, promovendo a inibição da carcinogênese (Molteni et al., 1995).
A genisteína, uma das duas mais importantes isoflavonas da soja, tem atraído muita atenção, não somente por causa do seu potencial efeito anti-estrogênico, mas também porque inibe várias enzimas envolvidas em processos de carcinogênese. A concentração da genisteína na maioria dos produtos de soja varia de 1-2 mg/g (Barnes et al., 1995). As populações orientais, que apresentam baixa incidência de câncer de mama e próstata, consomem de 28-80 mg de genisteína por dia, quase toda derivada de produtos de soja, enquanto que a ingestão diária de genisteína nos EUA é somente de 1-3 mg/dia (Wei et al., 1995). Zava \& Duwe (1997) sugerem que a genisteína é a única entre as isoflavonas que possui efeito potencial na inibição do crescimento de células cancerosas em concentrações fisiológicas e que a daidzeína só exerce algum efeito se combinada com a genisteína.

Lamartiniere et al. (1995) estudaram a atividade anti-carcinogênica da genisteína em um modelo animal de câncer de pele. A administração diária na dieta de 250 ppm de genisteína por 30 dias aumentou significativamente a atividade de enzimas antioxidantes na pele e no intestino delgado de camundongos. Estudos adicionais demonstraram que a genisteína inibiu significativamente a oncogênese induzida por 12-O-tetradecanoilphorbol-13-acetato (TPA) na pele dos animais em dose-dependente sendo que, baixos níveis de genisteína ( 1 a 5 mmol) prolongaram significativamente o tempo de latência do tumor e diminuíram sua multiplicidade em 
aproximadamente $50 \%$. Foi concluído que as propriedades antioxidantes e efeitos anti-proliferativos da genisteína podem ser responsáveis pelo seu efeito anti-carcinogênico.

Barnes et al. (1996) demonstraram que a genisteína é eficientemente absorvida no intestino e que, apesar de os níveis sangüíneos deste composto serem insuficientes para inibir o crescimento de um câncer de mama estabelecido, via mecanismos quimioterapêuticos, são suficientes para regular a proliferação de células epiteliais em câncer e sendo assim, podem exercer efeito quimiopreventivo.

Rao et al. (1997) investigaram os efeitos da genisteína na carcinogênese de cólon induzida por azoximetano (AOM) e estudaram o seu papel modulatório nos níveis de atividade da cicloxigenase (COX), 8-isoprostano e 15-hidroxiprostaglandina F2 $\alpha$-desidrogenase (15-PGDH) na mucosa colônica e em tumores de cólon de ratos machos da linhagem F344. Com 5 semanas de idade, grupos de ratos $\mathrm{F} 344$ machos foram alimentados com dieta controle (AIN-76A) ou uma dieta contendo 250 ppm de genisteína. Duas semanas mais tarde, todos os animais, exceto aqueles grupos tratados com veículo, receberam semanalmente injeções de AOM $(15 \mathrm{mg} / \mathrm{kg}$ de peso corporal) por duas semanas sucessivas. Todos os ratos foram alimentados com este regime por 52 semanas depois do tratamento com AOM, quando então foram sacrificados. Os tumores do cólon foram analisados histopatologicamente e quanto aos níveis de COX, 15-PGDH e 8-isoprostano sendo que o mesmo foi feito para a mucosa colônica. A administração de genisteína reduziu significativamente a multiplicidade e a invasão total do adenocarcinoma no cólon, comparado com a dieta controle. Também, a genisteína inibiu a atividade da 15-PGDH e os níveis de 8-isoprostano na mucosa colônica e nos tumores. Em contraste, não houve efeito significativo na atividade da COX. Estes resultados enfatizam que os efeitos biológicos da genisteína podem ser órgão-específicos, inibindo o câncer em alguns locais. A inibição dos níveis de 8-isoprostano indica seu possível efeito antioxidante. Os mecanismos exatos da melhora dos tumores de cólon pela genisteína, ainda não são elucidados; é provável que seus efeitos possam, em parte, ser relacionados à inibição da atividade de enzimas catabólicas.

Experimentos utilizando modelos animais com indução de câncer de mama e genisteína purificada têm demonstrado que o tempo de exposição dos animais aos isoflavonóides é crítico. Ratos tratados no períodos neonatal ou pré-pubertal com genisteína tem tido um tempo de latência maior antes do aparecimento de tumores de mama induzidos por 7,12-dimetilbenzoantraceno e expressiva redução no número de tumores. O mecanismo preventivo da genisteína ocorre, em parte, pela sua atividade estrogênica, a qual causa diferenciação das células das glândulas mamárias mais rápida. A administração de genisteína depois de 35 dias de idade apresentou alterações menores no risco ao câncer de mama (27\% de redução). Em contraste, em animais ovariectomizados a genisteína aumentou a proliferação de células cancerosas comparado com a dieta controle. Futuros estudos sobre o potencial anti-câncer das isoflavonas de soja devem investigar a interação destas com outros componentes fitoquímicos da soja e explorar modelos animais de câncer de mama nos quais, genes específicos podem ser ativados ou inativados (Barnes, 1997).

Wei et al. (1998) documentaram que a genisteína inibiu significativamente a carcinogênese de tumores de pele iniciados por 7, 12-dimetilbenzoantraceno (DMBA) e promovidos por 12-O-tetradecanoil-phorbol-13-acetato (TPA) em um modelo de carcinogênese de dois estágios. No estudo de iniciação, $10 \mu \mathrm{mol}$ de genisteína foram aplicados diariamente na pele de camundongos fêmeas SENCAR por uma semana, seguido pela iniciação com 10 $\mu \mathrm{mol}$ de DMBA. Os camundongos foram então tratados com TPA duas vezes por semana $(4 \mu \mathrm{g})$. A genisteína reduziu a incidência e a multiplicidade dos tumores de pele iniciados pelo DMBA em aproximadamente 20\% e $50 \%$, respectivamente. No outro experimento, Wei et al. (1998), conduziram dois estudos de promoção usando camundongos CD-1 e SENCAR. No primeiro estudo, camundongos CD-1 foram iniciados com $100 \mathrm{nmol}$ de DMBA, seguindo-se com a administração de 1-5 $\mu \mathrm{mol}$ de genisteína/4 $\mu$ g de TPA, duas vezes por semana. No segundo estudo, camundongos SENCAR foram iniciados com 10 nmol de DMBA e em seguida receberam um regime de 5, 10 e $20 \mu \mathrm{mol}$ de genisteína/2 $\mu$ g de TPA. Ambos os estudos mostraram que a genisteína inibiu substancialmente a promoção de tumor de pele induzido por TPA pela redução da multiplicidade dos tumores em aproximadamente $60 \mathrm{e}$ $75 \%$, respectivamente. Entretanto, a incidência de tumores pareceu não ser afetada. Estudos mecanísticos mostraram que a genisteína inibiu o aparecimento de alterações mutagênicas no DNA induzidas por DMBA e substancialmente suprimiu as respostas inflamatórias estimuladas por TPA na pele dos animais em aproximadamente $60 \%$ ou mais. Desta maneira, estes resultados sugerem que a genisteína exerce efeitos anti-iniciais e anti-promocionais na carcinogênese de pele provavelmente através da inibição do desenvolvimento de alterações no DNA e inibição de eventos oxidativos e inflamatórios in vivo.

\section{Isoflavonas versus osteoporose}

A osteoporose é uma enfermidade crônica que ocorre quando a taxa de degradação óssea dos osteoclastos excede à sua formação. Recentes estudos epidemiológicos tem sugerido que a incidência de osteoporose pós-menopausa é menor na Ásia que no ocidente. Uma das possíveis explicações para esta diferença se baseia na elevada ingestão de produtos de soja, ricos em isoflavonas, pelas mulheres asiáticas (Potter et al., 1998). Por outro lado, estudos de massa óssea em modelos-animais demonstram um efeito bifásico das isoflavonas na retenção 
óssea com altas doses apresentando menores benefícios e menores doses apresentando melhoria na retenção da massa óssea (Molteni et al., 1995). Outros estudos com animais têm mostrado que extratos enriquecidos com isoflavonas aumentam a massa óssea (Anderson et al., 1998). Potter et al. (1998) demonstraram melhoria na densidade óssea em indivíduos tratados com preparações à base de soja enriquecidas com isoflavonas, por um período de 6 meses. Estudos in vitro, além de confirmar estas evidências, estendem os conhecimentos da resposta bifásica observada em modelos-animais, estabelecendo que ambos, a genisteína e o estradiol são tóxicos às células ósseas em altas concentrações $\left(10^{-4} \mathrm{M}\right)$ e que, em baixas concentrações, a genisteína e o estradiol aumentam a produção de biomarcadores ósseos e fosfatase alcalina de maneira similar (Williams et al., 1998).

Vários possíveis mecanismos têm sido sugeridos para explicar os efeitos benéficos das isoflavonas de soja no tecido ósseo, os quais podem ajudar a prevenir o desenvolvimento da osteoporose. Tem-se sugerido que os osteoblastos e os osteoclastos são as células alvo para a ação da genisteína e da daidzeína. Estudos em cultura de células semelhantes a osteoblastos sugerem que a genisteína combina com receptores de estrógenos e exerce seus efeitos pelo mesmo mecanismo que este hormônio. Por outro lado, ela pode também exercer efeitos por outros mecanismos, independentes de receptores para estrógenos (Williams et al., 1998).

Alguns investigadores têm sugerido que a genisteína inibe a topoisomerase II, interferindo assim, com a progressão do ciclo celular, enquanto que outros sugerem que a genisteína ativa receptores peptídicos ligados à membrana, iniciando outros efeitos independentes de estrógenos. Por exemplo, os osteoclastos são dependentes da atividade de receptores tirosina quinase (PTK), então os inibidores de PTK são candidatos à prevenção da osteoporose. A genisteína e a daidzeína, isoflavonas naturais, são inibidoras de PTK e poderiam agir por este mecanismo (Williams et al., 1998).

Erdman Jr et al. (1996) investigaram mudanças na densidade óssea e no conteúdo mineral do osso antes e seguindo um período de 6 meses de alimentação. Mulheres em período pós-menopausa receberam $40 \mathrm{~g}$ de proteína por dia, proveniente de isolado protéico de soja com 1,39 mg de isoflavonas/g de proteína (IPS) ou com 2,25 mg de isoflavonas/g de proteína (IPS+) ou caseína (controle). Os resultados indicaram aumentos significativos no conteúdo mineral e densidade do osso nos grupos IPS e IPS + quando comparados com o controle. Apesar de ter sido um estudo à curto prazo, estes resultados sugerem o papel potencial das isoflavonas de soja na manutenção da saúde do osso.

Ishida et al. (1998) investigaram os efeitos das isoflavonas, daidzina e genistina (precursoras da genisteína e daidzeína) na perda óssea em ratas ovariectomizadas (OVX) alimentadas com dietas deficientes em cálcio. As isoflavonas foram administradas oralmente aos animais por 4 semanas. Os ossos do fêmur destes animais apresentaram significativamente menor densidade, força de quebra, cinzas, peso e conteúdo de cálcio e fósforo quando comparados com os animais não OVX. Estas mudanças foram prevenidas nos animais que receberam daidzina e genistina por 4 semanas em uma dose de $50 \mathrm{mg} / \mathrm{kg} /$ dia e nos animais que receberam uma estrona subcutânea $(7,5 \mu \mathrm{g} / \mathrm{kg} / \mathrm{dia})$ como controle positivo. A ovariectomia causou atrofia do útero e aumentou a taxa de excreção urinária de piridinoline e desoxipiridinoline. Isto foi prevenido pela administração de daidzina e estrona, não ocorrendo com a genistina. O efeito preventivo do tratamento com daidzína na perda óssea em ratas ovariectomizadas parece ser devido à supressão do turnover do osso e a genistina possui um mecanismo diferente da daidzína.

Yamaguchi \& Gao (1998) estudaram, in vitro, os efeitos da genisteína e da genistina no componentes ósseos em tecidos femurais obtidos de ratas fêmeas em idade avançada. Estes tecido foram cultivados por 24 horas em um meio contendo ou veículo ou genisteína $\left(10^{-8}-10^{-5} \mathrm{M}\right)$ ou genistina $\left(10^{-7}-10^{-5} \mathrm{M}\right)$. A presença de genisteína e genistina causou um aumento significativo na atividade da fosfatase alcalina, no conteúdo de DNA e cálcio nos tecidos. O efeito da genisteína foi maior que o da genistina. A presença de sulfato de $\mathrm{Zn}\left(10^{-5} \mathrm{M}\right)$ causou um aumento significativo na atividade da fosfatase alcalina elevada pela genisteína e nos conteúdos de DNA e cálcio, o que não ocorreu com a genistina. Então estes resultados sugerem que a genisteína e a genistina possuem efeito anabólico no metabolismo ósseo em tecidos femorais de ratas em idade avançada e que o efeito da genisteína é aumentado pela presença do $\mathrm{Zn}$, um elemento traço essencial.

O efeito bifásico da genisteína no tecido ósseo de ratas ovariectomizadas (OVX) foi investigado por Anderson et al. (1998). Estes autores encontraram resultados consistentes com outros resultados recentes da literatura em células isoladas e tecidos reprodutivos, ou seja, doses mais baixas de genisteína agem similarmente a estrógenos com um efeito benéfico ao tecido ósseo, mas em doses elevadas, podem exercer efeitos potencialmente adversos às funções celulares das células e tecidos ósseos.

\section{Isoflavonas versus doenças cardiovasculares}

As enfermidades cardiovasculares incluem o infarto e a arteriosclerose, que podem causar problemas vasculares, como o derrame cerebral. A causa principal destas enfermidades é a obstrução do fluxo de sangue nos vasos sangüíneos em virtude da formação de placas gordurosas que, à medida que aumentam de tamanho, reduzem o fluxo até que, em caso extremo, chegam a obstruí-lo por completo. Um dos principais fatores que levam à ocorrência destas enfermidades são os níveis elevados de colesterol no sangue, pois este é um dos maiores constituintes das placas de ateroma (Grundy, 1983). 
O consumo de soja tem sido associado à redução de doenças cardiovasculares, especialmente da arteroesclerose em modelos animais. Em adição, evidências epidemiológicas sugerem que populações que consomem dietas ricas em soja e seus produtos apresentam uma menor taxa de mortalidade por doenças coronarianas (Lichtenstein, 1998). Apesar de estudos em animais sugerirem que a proteína de soja reduz o colesterol sanguíneo, estudos similares em humanos tem apresentado resultados menos consistentes. A presença ou ausência de isoflavonas pode ser um fator que causa confusão. Esta fração, principalmente genisteína e daidzeína, tem apresentado efeito hipocolesterolemiante em animais e humanos (Huff et al., 1977).

Estudos em animais demonstram que as isoflavonas parecem ser essenciais no efeito de redução do colesterol sanguíneo. Isolados protéicos de soja que tiveram as isoflavonas removidas mostraram-se normo ou hipercolesterolêmicos. As concentrações plasmáticas de Lipoproteína de Baixa Densidade (LDL-colesterol) foram significativamente menores em macacos Rhesus tratados com isoflavonas de soja quando comparados com macacos tratados com formulados de soja sem isoflavonas. Estudos adicionais têm demonstrado que as isoflavonas não só desempenham um papel importante na regulação de lipoproteínas, reduzindo LDL e aumentando Lipoproteína de Alta Densidade (HDL), mas também protegem contra o desenvolvimento de placas de ateroma (Anthony et al., 1996).

Em outro estudo, Honore et al. (1997) examinaram os efeitos das isoflavonas na reatividade vascular coronária em macacos Rhesus fêmeas. A arteriosclerose foi induzida e os animais foram alimentados com dietas à base de soja por 6 meses, idênticas em composição, exceto que as isoflavonas foram extraídas de uma dieta (low-isoflavones) e mantidas intactas em outra (high-isoflavones). Resultados mostraram que as artérias das fêmeas do grupo low-isoflavones se comprimiram enquanto que as artérias das fêmeas do grupo high-isoflavones se dilataram. A administração intravenosa de genisteína causou dilatação nas artérias das fêmeas do grupo low-isoflavones. Concluiu-se que as isoflavonas de soja, como os estrógenos de mamíferos, aumentam a resposta de dilatação em artérias arterioscleróticas de fêmeas de macacos Rhesus.

Os mecanismos postulados são tipicamente baseados na ligação das isoflavonas a receptores estrógenos dentro das células de maneira semelhante ao estradiol, o que influenciaria no metabolismo do colesterol e das lipoproteínas. Em adição, as isoflavonas poderiam agir como antioxidantes, inibindo o processo trombótico e bloqueando a proliferação de células musculares lisas nas paredes das artérias (Potter et al., 1996). Por outro lado, o aumento do consumo de produtos de soja pode implicar redução do consumo de alimentos ricos em gorduras saturadas e colesterol e, sendo assim, exercem um efeito indireto na redução do colesterol sangüíneo (Huff et al., 1977).

A possibilidade de que o aumento de risco de doenças cardiovasculares associado com menopausa, a qual é dita ser amenizada pela soja, pode ser reduzida com isoflavonas de soja, foi testada em 21 mulheres. Foram avaliados os efeitos de $80 \mathrm{mg}$ diárias de isoflavonas (45 de genisteína) em um período de 5 a 10 semanas. A elasticidade arterial, a qual diminui com a idade, melhorou em $26 \%$ quando comparada com um grupo placebo. A pressão arterial e os lipídios plasmáticos não foram afetados. A capacidade vasodilatadora da microcirculação foi medida em 9 mulheres. A dilatação mediada por acetilcolina na musculatura dos vasos destas mulheres foi similar aos grupos placebo e genisteína. A capacidade de oxidação da LDL medida in vitro não foi alterada. Então, uma importante medida da saúde arterial - elasticidade dos vasos - foi significativamente melhorada em mulheres em menopausa cujo tempo de exposição às isoflavonas foi semelhante às convencionais terapias de reposição hormonal (Nestel et al., 1997).

Acredita-se que a oxidação da LDL colesterol ocorre no interior das artérias quando estas partículas se tornam isoladas dos antioxidantes hidrossolúveis circulantes. Tikkanen et al. (1998) hipotetizaram que as isoflavonas poderiam ser incorporadas nas lipoproteínas e possivelmente poderiam proteger contra a oxidação, a qual é considerada aterogênica. Para verificar tal hipótese, 6 voluntários saudáveis receberam 3 porções de soja (12 mg de genisteína e 7 mg de daidzeína), diariamente, por um período de 3 semanas. As LDL foram isoladas do sangue ao final de 2 semanas antes do consumo da soja e após as 3 semanas de consumo. Observou-se um grande aumento nos níveis de isoflavonas plasmáticas durante o período de alimentação com soja, mas somente uma pequena quantidade foi associada com as lipoproteínas (menos que $1 \%$ na fração LDL). As LDL foram submetidas à oxidação in vitro mediada por cobre. Comparado com os valores da soja, as fases lag da curva de oxidação da LDL foram prolongadas em aproximadamente 20 minutos durante a ingestão de soja, indicando um redução na suscetibilidade à oxidação. Estes resultados sugerem que a ingestão de antioxidantes derivados de soja, tais com a genisteína e a daidzeína, podem promover proteção contra modificações oxidativas da LDL. Como apenas pequenas quantidades destas substâncias foram detectadas em LDL purificada, partículas de LDL modificadas podem ter sido produzidas in vivo pelas isoflavonas circulantes, promovendo resistência à oxidação ex vivo.

Kirk et al. (1998) conduziram um estudo para determinar se as isoflavonas de soja conferem proteção contra a arteroesclerose em camundongos e se elas reduzem os níveis de colesterol sérico e oxidação de lipoproteínas. Camundongos deficientes em receptores para LDL (LDLr-null) e camundongos C57BL/6 foram alimentados com dietas baseadas em proteína de soja, ricas em gordura e com isoflavonas presentes (IF + ), ou dietas nas quais as isoflavonas e possivelmente outros componentes, foram extraídos (IF-). Devido ao fato de os animais LDLr-null desenvolverem arteroesclerose e hipercolesterolemia após um tempo mínimo de exposição à dietas ricas em gorduras, eles foram alimentados por 6 semanas enquanto que os $\mathrm{C} 57 \mathrm{BL} / 6$ foram alimentados por 10 semanas. Os níveis plasmáticos de colesterol não 
diferiram entre LDLr-null alimentados com IF- e aqueles alimentados com IF+, mas foram $30 \%$ menores nos camundongos $\mathrm{C} 57 \mathrm{BL} / 6$ alimentados com dieta IF + do que naqueles alimentados com dieta IF-. A susceptibilidade da LDL à modificações oxidativas, não foi alterada pelo consumo de isoflavonas. Todos os animais desenvolveram arteroesclerose, mas a área de lesão foi significativamente menor nos camundongos $\mathrm{C} 57 \mathrm{BL} / 6$ alimentados com dieta IF+ quando comparados com aqueles alimentados com dieta IF-. Estes resultados sugerem que as isoflavonas de soja podem reduzir níveis de colesterol pelo aumento da atividade do receptor LDL, e a redução dos níveis de colesterol pode oferecer proteção contra a arteroesclerose.

\section{Isoflavonas versus diabetes mellitus}

O diabetes mellitus é uma síndrome caracterizada por níveis elevados de glicose sangüínea em situações de jejum, de forma crônica; além disso é acompanhado por alterações no metabolismo de carboidratos, lipídios e proteínas, sendo essas alterações uma conseqüência do déficit da secreção ou da ação da insulina (Pallardo, 1977). A sobrevida dos pacientes diabéticos é acompanhada de numerosas complicações tanto metabólicas (hiperglicemia, hipoglicemia, dislipidemia) quanto vasculares (nefropatias, retinopatias e neuropatias) (Esminger et al., 1994). As formas clínicas consideradas clássicas do diabetes são: o diabetes mellitus insulino dependente (DMID) e o diabetes mellitus não insulino dependente (DMNID) que é mais freqüente (Pallardo, 1977).

A insulina é o principal hormônio que regula o metabolismo da glicose. Nas células, a insulina ativa o transporte de glicose e aminoácidos, o metabolismo de glicogênio e lipídios, a síntese protéica e a transcrição de genes específicos (Kahn, 1998). As ações biológicas da insulina são iniciadas pela ligação deste hormônio a receptores específicos localizados nas membranas plasmáticas das células responsivas. Ênfase tem sido dada em como o sinal inicial promovido pela ligação da insulina ao receptor, é convertido aos efeitos finais deste hormônio no crescimento e metabolismo, como esta sinalização é alterada em estados de resistência à insulina, tais como no DMNID e qual é o impacto genético nestas funções (Alberts et al., 1997).

Nas celulas, os receptores para insulina são enzimas estimuladas por ela própria, com atividade de proteína tirosina quinase. O mecanismo geral de ação da insulina inicia-se com a ligação deste hormônio aos receptores tirosina quinases na membrana celular. A ligação da insulina a estes receptores, que é dependente das concentrações plasmáticas de glicose, desencadeia uma série de respostas intracelulares que irão culminar, entre outras coisas, no estímulo à secreção da própria insulina. Este processo é também mediado por sinalizadores intermediários tais como, o cálcio e o AMP cíclico (cAMP) (Alberts et al., 1997). Estudos têm demonstrado que o cálcio $\left(\mathrm{Ca}^{2+}\right)$ intracelular está intimamente relacionado à secreção de insulina. O efeito chave do $\mathrm{Ca}^{2+}$ na iniciação da secreção da insulina envolve a ativação de uma proteína quinase dependente de $\mathrm{Ca}^{2+} /$ calmodulina. A potencialização da secreção por agentes ativadores da proteína quinase $\mathrm{A}$ ou $C$ parece envolver um aumento na sensibilidade do sistema secretório para o $\mathrm{Ca}^{2+}$. A identificação das quinases e fosfatases responsáveis não é conhecida, mas a presença nas membranas de células $\beta$ de várias quinases não dependentes de $\mathrm{Ca}^{2+}$ ou cAMP, incluindo a tirosina quinase, é documentada juntamente com a presenças de ambas as proteínas fosfatases dependentes e independentes de $\mathrm{Ca}^{2+}$. A fosforilação de proteínas está também envolvida nos fluxos de $\mathrm{Ca}^{2+}$ das células $\beta$ e evidência é apresentada de que a ativação da proteína quinase $C$ inibe a sinalização pela redução do influxo de $\mathrm{Ca}^{2+}$ dentro da células $\beta$ (Ashcroft, 1994).

Devido ao seu efeito inibidor da proteína tirosina quinase, a genisteína vem sendo estudada como um composto regulador da secreção de insulina, cuja liberação é controlada por mecanismos complexos de sinalização celular que envolvem a ação destes receptores (Kahn, 1998). Os efeitos benéficos que vêm sendo observados em estudos com animais e culturas de células sugerem que a genisteína pode ser uma alternativa no tratamento do diabetes, principalmente do tipo 2.

Efeitos da genisteína na liberação de insulina foram estudados usando células MIN6, que são células pertencentes a uma linha de insulinoma, sensíveis à glicose. Em concentrações não estimulatórias de glicose, a genisteína não afetou a liberação de insulina. Entretanto, em concentrações estimulatórias (mínimo de $20 \mu \mathrm{g} / \mathrm{ml}$ ) a genisteína aumentou significativamente a liberação de insulina. O conteúdo de cAMP nas células MIN6 foi também elevado significativamente pela genisteína e a relação dose-dependente entre genisteína e acumulação de cAMP foi consistente com a relação entre genisteína e liberação de insulina. Estes efeitos foram inibidos por antagonistas de cálcio ou pela omissão de cálcio extra-celular. O acúmulo de cAMP pode ter ocorrido, em parte, devido à inibição da fosfodieterase pela genisteína. Estes resultados sugerem que a genisteína aumenta a liberação de insulina induzida por glicose devido à sua contribuição para o acúmulo de cAMP e modulação do cálcio, o que depende do cálcio extracelular (Ashcroft, 1994).

$O$ efeito de inibidores de tirosina quinases na secreção de insulina e proliferação de ilhotas foi examinado em culturas de células de ilhotas de Langerhans por Sorenson et al. (1994). Quando as ilhotas foram expostas a $100 \mathrm{mmol}$ de genisteína, um aumento de 5 a 10 vezes na secreção de isulina foi observado. O efeito na secreção de insulina foi detectado dentro de 1 hora e foi mantido por, no mínimo, 4 dias. A sensibilidade das ilhotas expostas à genisteína foi dramaticamente aumentada como demonstrado por uma elevação na curva de resposta doseglicose a menores concentrações de glicose. Em contraste, a proliferação das células das ilhotas foi dramaticamente reduzida na presença da genisteína.

Jonas et al. (1995) avaliaram os efeitos agudos da genisteína no estímulo à secreção de insulina em células $\beta$ do pâncreas de camundongos. A genisteína provocou um 
aumento na liberação de insulina, reversível e dependente da concentração (10 a $100 \mu \mathrm{mol})$. Este efeito foi marginal na liberação basal ou na presença de nutrientes não metabolizados e muito maior na presença de glicose. $\mathrm{O}$ aumento na liberação da insulina causado por $100 \mathrm{mmol}$ de genisteína foi cessado pela adrenalina ou omissão do cálcio extracelular, e não foi acompanhado por qualquer aumento nas concentrações de CAMP, inositol fosfato ou adenina nucleotídeo. Apesar da genisteína ter inibido sensivelmente os canais de potássio sensíveis ao ATP, este efeito não explica a sua ação na liberação da insulina porque esta ocorreu mesmo quando estes canais foram bloqueados. A genisteína também foi efetiva quando os canais de potássio sensíveis ao ATP foram abertos. Paradoxalmente, a genisteína diminuiu o influxo de cálcio nas células $\beta$. A daidzeína, um análogo da genisteína, não afetou as tirosina quinases, foi sensivelmente menos potente nos canais de cálcio e potássio, mas aumentou a secreção de insulina de maneira similar.

Drake \& Posner (1998) sugeriram que a proteína tirosina fosfatase (PTPs) desempenham um papel crítico na regulação da ação da insulina em parte através da desfosforilação da forma ativa do receptor para insulina (IRK) e atenuação da sua atividade de tirosina quinase. Após a ligação da insulina, o IRK ativado é rapidamente internalizado no aparelho endossomal. Estudos em fígado de rato sugerem um processo regulatório complexo por meio do qual as PTPs podem agir, via desfosforilação seletiva do IRK, para modular sua atividade de maneira positiva e negativa. A genisteína tem mostrado ação ativadora das PTPs, estimulando a secreção de insulina. Desta maneira, a identificação dos mecanismos de ação da genisteína nestas proteínas, facilitaria o desenvolvimento de alternativas no tratamento do diabetes melito.

Os mecanismos pelos quais as isoflavonas, especialmente a genisteína, exercem este efeito ainda não são bem elucidados. Sabe-se que a genisteína é um potente inibidor das proteínas tirosina quinases (receptores para insulina), e sua ligação a estes receptores promove aumento da secreção de insulina. Como as pesquisas vem demonstrando que, na presença da genisteína ligada ao receptor, ocorre acúmulo de cAMP e cálcio intracelulares, pode-se inferir que um possível mecanismo de ação destes compostos seria via ativação das proteínas quinases (A e C). As proteínas quinases A e C ativam cascatas de fosforilações de proteínas que culminam com a transcrição de genes para a insulina, o que aumenta a secreção deste hormônio. Em contraste, estas proteína quinases, via de regra, são ativadas por receptores de membrana ligados à proteína G (outra classe de receptores de membrana) e não por receptores tirosina quinases. De alguma maneira, a inativação dos receptores tirosina quinases pela genisteína, promoveria a ativação das proteína quinases A e C, via mecanismos dependentes de cálcio e cAMP. Em adição, tem sido observado que a daidzeína promove um aumento na secreção de insulina proporcional à genisteína e, a daidzeína não é um inibidor de tirosina quinases, sugerindo mais uma vez, que o mecanismo que leva ao aumento da secreção da insulina envolve muito mais do que a inativação dos receptores tirosina quinases (Figura 2).
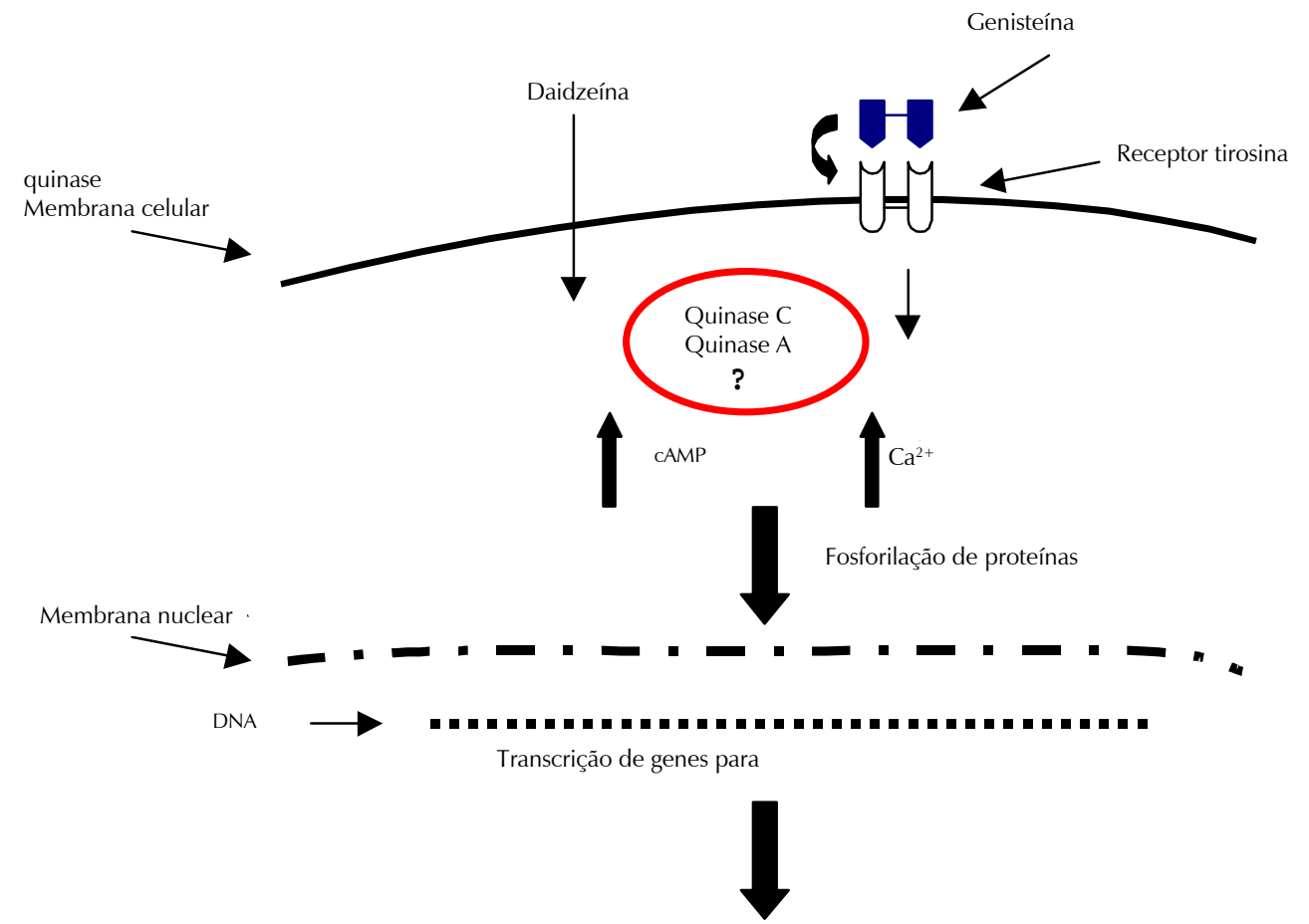

AUMENTO DA SECREÇÃO

Figura 2. Possíveis mecanismos de ação das isoflavonas no controle da secreção de insulina. 


\section{CONSIDERAÇÕES FINAIS}

Estes estudos são de extrema importância devido à alta incidência de doencas crônicas na maioria das populações e podem contribuir para se encontrar maneiras alternativas, não medicamentosas, para o controle destas.

\section{REFERÊNCIAS BIBLIOGRÁFICAS}

ALBERTS, B., BRAY, D., LEWIS, J. Biologia molecular da célula. 3.ed. Porto Alegre : Artes Médicas, 1997. 1294 p.

ANDERSON, J.J.B., GARNER, S.C. Phytoestrogens and human function. Nutrition Today, v.32, n.6, p.232-239, 1997.

ANDERSON, J.J., AMBROSE, W.W., GARNER, S.C. Bhiphasic effects of genistein on bone tissue in the ovariectomized, lactating rat model. Proceedings of the Society for Experimental Biology and Medicine, New York, v.217, n.13, p.345-350, 1998.

ANTHONY, M.S., CLARKSON, T.B., HUGHES, C.L. Soybean isoflavones improve cardiovascular risck factors affecting the reproductive system of peripubertal rhesus monkeys. Journal of Nutrition, Bethesda, v.126, p.43-50, 1996.

ASHCROFT, S.J. Protein phosphorilation and beta-cell function. Diabetologia, Berlin, v.37, p.21S-29S, 1994. Supplement 2.

BARNES, S. The chemopreventive properties of soy isoflavonoids in animal models of breast cancer. Breast Cancer Research and Treatment, The Hague, v.46, n.2-3, p.169-179, 1997.

BARNES, S., PETERSON, T.G., COWARD, L. Rationale for the use of genistein-containing soy matrices in chemoprevention trials for breast and prostate cancer. Journal of Cellular Biochemistry, New York, v.22, p.181S-185S, 1995. Supplement.

BARNES, S., SFAKIANOS, J., COWARD, L. Soy isoflavonoids and cancer prevention. Underlying biochemical and pharmacological issues. Advances in Experimental Medicine and Biology, New York, v.401, p.87-100, 1996.

BRANDI, M.L. Natural and syntetic isoflavones in the prevention and treatment of chronic diseases. Calcified Tissue International, New York, v.61, p.1S-8S, 1997. Supplement 1.

CAMERON, E., PAULING, L. Cancer and vitamin C. New York : Linus Pauling Institute of Science and Medicine, 1979. 238p.

DRAKE, P.G., POSNER, B.I. Insulin receptor-associated protein tyrosin phosphatase (s): role in insulin action. Molecular and Cellular Biochemistry, The Hague, v.182, n.1-2, p.79-89, 1998.

ERDAMAN Jr, J.W., STILLMAN, R.J., LEE, K.F. Short-term effect of soybean isoflavones on bone in postmenopausal women. In: INTERNATIONAL SYMPOSIUM ON THE ROLE OF SOY IN PREVENTING AND TREATING CHRONIC DISEASE, 2., 1996, Belgium. Program and Abstract Book. Belgium, 1996. p.21.

ESMINGER, A.H., ESMINGER, M.E., KONLANDE, J.F. Diabetes mellitus: foods and nutrition encyclopedia. London : RRC, 1994. p.555-575.

GRUNDY, S.M. Absorption and metabolism of dietary cholesterol. Annual Review of Nutrition, Palo Alto, v.3, p.71-96. 1983.

HONORE, E.K., WILLIAMS, J.K., ANTHONY, M.S. Soy isoflavones enhance coronary vascular reactivity in atherosclerotic female macaques. Fertility and Sterility, Birmingham, v.67, n.1, p.148-54, 1997.

HUFF, M.W., HAMILTON, R.M.G., CARROL, K.K. Plasma cholesterol levels in rabbits fed low fat, cholesterol-free, semipurified diets: effects od dietary proteins, protein hydrolisates and amino acid mixtures. Atherosclerosis, Limerick, v.28, p.186-195, 1977.

ISHIDA, H., UESUGI, T., HIRAI, K. Preventive effect of the plant isoflavones, daidzin and genistin, on bone loss in ovariectomized rats fed a calcium-deficient diet. Biological and Pharmaceutical Bulletin, Tokyo, v.21, n.1, p.62-66, 1998.

JONAS, J.C., PLANT, T.D., GILON, P. Multiple effects and stimulation of insulin secretion by the tyrosine kinase inhibitor genistein in normal mouse islets. British Journal of Pharmacology, London, v.114, n.4, p.872-880, 1995.

KAHN, C.R. Section on cellular and Molecular physiology. JOSLIN Magazine, v.11, n.3., p.17, 1998. (Research Report. 199798)

KIRK, E.A., SHUTERLAND, P., WANG, S.A. Dietary isoflavones reduce plasma cholesterol and atherosclerosis in $\mathrm{C} 57 \mathrm{BL} / 6$ mice, but not LDL receptor-deficient mice. Journal of Nutrition, Bethesda, v.128, n.6, p.954-959, 1998.

KURZER, M.S., XU, X. Dietary phytoestrogens. Annual Review of Nutrition, Palo Alto, v.17, p.353-381, 1997.

LAMARTINIERE, C.A., MOORE, J., HOLLAND, M. et al. Neonatal genistein chemopreventives mammary cancer. Proceedings of the Society for Experimental Biology and Medicine, New York, v.208, n.1, p.120-123.

LICHTENSTEIN, A.H. Soy protein, isoflavones and cardiovascular disease risk. Journal of Nutrition, Bethesda, v.128, n.10, p.1589-1592, 1998.

MOLTENI, A., BRIZIO-MOLTENI, L., PERSKY, V. In vitro hormonal effects of soybean isoflavones. Journal of Nutrition, Bethesda, v.125, p.751-756, 1995. Supplement 3.

NESTEL, P.J., YAMASHITA, T. SASAHARA, T. Soy isoflavones improve systemic arterial compliance but not plasma lipids in menopausal and perimenopausal women. Arterioscler Thromb Vasc Biol, v.17, n.12, p.3392-3398, 1997.

PALLARDO, J.P.M. Avances em diabetes. Madrid : Grupo Aula Médica, 1977. 269p.

POTTER, S.M., PERTILE, J., BERBER-JIMENEZ, M.D. Soy protein concentrate and isolated soy protein similarly lower blood serum cholesterol but differently affect thyroid hormones in hamsters. Journal of Nutrition, Bethesda, v.126, n.8, p.2007-2011, 1996.

POTTER, S.M., BAUM, J.A., TENG, H. Soy protein and isoflavones: Their effects on blood lipids and bone density in postmenopausal women. American Journal of Clinical Nutrition, Bethesda, v.68, n.6, p.1375S-1379S, 1998. Supplement.

RAO, C.V., WANG, C.X., SIMI, B. Enhancement of experimental colon cancer by genistein. Cancer Research, Baltimore, v.57, n.17, p.3717-3722, 1997.

SETCHELL, K.D. Phytoestrogens: the biochemistry, physiology, and implications for human health of soy isoflavones. American Journal Clinical of Nutrition, Bethesda, v.134, n.6, p.1333S-1343S, 1998. Supplement.

SORENSON, R.L., BRELJE, T.C., ROTH, C. Effect of tyriosine kinase inhibitors on islet od Langerhans: evidence for tyrosine 
kinases in the regulation of insulin secretion. Endocrinology, Baltimore, v.134, n.4, p.1975-1978, 1994.

TIKKANEN, M.J., WAHALA, K., OJALA, S. Effect of soybean phytoestrogen intake on low density lipoprotein oxidation resistance. Proceedings of the National Academy of Sciences of the United States of America, Washington DC, v.95, n.6, p.3106-3110, 1998.

TOLONEM, M. Vitamins and minerals in health and nutrition. London : Ellis Horwood Series in Food Science and Tecnology, 1990. $231 \mathrm{p}$.

WEI, H., BOWEN, R., CAI, Q. Antioxidant and antipromotional effects of the soybean isoflavone genistein. Proccedings of the Society for Experimental Biology and Medicine, New York, v.208, n.1, p.124-130, 1995.

WEI, H. BOWEN, R., ZHANG, X. Isoflavone genistein inhibits the initiation and promotion of two stage skin carcinogenesis in mice. Carcinogenesis, New York, v.19, n.8, p.1509-1514, 1998.
WILLIAMS, J.P., JORDAN, S.E., BARNES, S. Tyrosine kinase inhibitor effects on osteoclastic acid transport. American Journal of Clinical Nutrition, Bethesda, v.68, n.6, p.1369S-1374S, 1998. Supplement.

YAMAGUCHI, M, GAO, Y.H. Anabolic effect of genistein and genistin on bone metabolism in the femoral-metaphyseal tissues of elderly rats: the genistein effect is enhanced by zinc. Molecular and Cellular Biochemistry, The Hague, v.178, n.1-2, p.377-382, 1998.

ZAVA, D.T., DUWE, G. Estrogenic and antiproliferative properties of genistein and other flavonoids in human breast cancer cells in vitro. Nutrition and Cancer, Hillsdale,v.27, n.1, p.31-40, 1997.

Recebido para publicação em 23 de dezembro de 1999 e aceito em 5 de abril de 2000 . 